\title{
ASOSIASI JENIS ULIN (EUSYDEROXILON ZWAGERI) DENGAN JENIS POHON DOMINAN DI KAWASAN KONSERVASI SANGKIMA, TAMAN NASIONAL KUTAI, KALIMANTAN TIMUR
}

Association of Ironwood (Eusyderoxilon zwageri ) with Other Dominant Tree Species in Sangkima Conservation Area, Kutai National Park, East Kalimantan

\author{
Nilam Sari \& Rizki Maharani \\ Balai Besar Penelitian dan Pengembangan Ekosistem Hutan Dipterokarpa, Jl. AW. Syahrani No. 68, \\ Sempaja, Samarinda, Kalimantan Timur, Indonesia. \\ Telp. 0541206364, Fax. 0541742298, \\ Email:nnilamsachair@gmail.com, rizmaannisa@yahoo.com
}

Diterima : 7 Maret 2016, direvisi : 22 Juni 2016, disetujui : 26 Juli 2016

\begin{abstract}
ABSTRAK
Ulin (Eusyderoxilon zwageri) merupakan salah satu hasil hutan favorit yang bernilai tinggi, tapi keberadaannya hampir punah akibat tingginya laju penebangan illegal oleh masyarakat di sekitar maupun luar hutan. Oleh karena itu, perlu dilakukan suatu penelitian mengenai asosiasi jenis ulin (E. zwageri) di hutan alam agar dapat digunakan sebagai bahan pertimbangan dalam upaya untuk mengoptimalkan budidaya jenis ulin. Penelitian ini bertujuan untuk mengetahui asosiasi jenis ulin dengan pohon-pohon dominan di kawasan Konservasi Sangkima Taman Nasional Kutai dalam rangka menunjang pembudidayaan jenis-jenis tersebut dalam rangka pengembangan tanaman ulin. Penelitian dilakukan dengan membuat plot yang diletakkan secara purposive, dengan ukuran $100 \mathrm{~m}$ x 100m yang dibagi dalam 25 petak berukuran $20 \mathrm{~m}$ x 20m. Data yang dikumpulkan adalah inventarisasi jenis-jenis pada tingkat pohon berdiameter diatas $10 \mathrm{~cm}$. Pengambilan data posisi pohon (x dan y) dan titik koordinat dilakukan untuk seluruh jenis pada tingkat pohon. Hasil penelitian menunjukkan ulin memiliki Indeks Nilai Penting (INP) tertinggi dari jenis-jenis lainnya, yaitu 59,83\% dan berasosiasi secara positif dengan jenis $S$. leprosula dan F. albifila di kawasan Konservasi Sangkima.
\end{abstract}

Kata kunci : ulin, hasil hutan, asosiasi jenis, INP, kawasan konservasi

\section{ABSTRACT}

Ironwood (E. zwageri) is one of high value forest products. However, this species faces a high risk of extinction due to high rate of illegal logging, that conducted by people who live near forests. Therefore, it is necessary to examine ironwood-habitat associations in natural forests to be used as a basis for optimizing ironwood cultivation. This study aims to investigate the association of ironwood trees with other dominant tree species in Sangkima Conservation Area, Kutai National Park in order to support ironwood cultivation development. This study used purposive sampling method by establishing a plot measuring $100 \mathrm{~m} \times 100 \mathrm{~m}$, which was divided into 25 subplots, each of the size $20 \mathrm{~m} \times 20 \mathrm{~m}$. All trees with diameter $\geq 10 \mathrm{~cm}$ were recorded. This study also collected tree positions ( $x$ and $y$ ) and point coordinate data. Result shows that ironwood has highest Importance Value Index (IVI), that is about 59.83\% and positively associated with S. leprosula dan F. albifila.

Keywords: ironwood, forest products, species association, IVI, conservation area

\section{PENDAHULUAN}

Pohon ulin (E. zwageri) merupakan jenis favorit untuk perdagangan lokal maupun ekspor. Ulin atau kayu besi (E. zwageri Teijsm \& Binn) adalah salah satu jenis pohon di Indonesia yang mempunyai nilai sosial budaya dan ekonomi tinggi. Jenis ini tidak bisa dipisahkan dengan budaya masyarakat Sumatera dan Kalimantan yang umumnya mempunyai budaya membuat rumah dari kayu berbentuk panggung yang terletak di pinggir sungai atau rawa, dan hanya kayu ulin yang mampu bertahan, bahkan akan semakin kuat dan awet bila digunakan pada daerah-daerah bertanah basah atau tergenang air. Selain itu, ulin juga tahan terhadap serangan hama serangga penggerek kayu (Wahjono dan Imanuddin, 2011; Pradjadinata dan Murniati, 2014).

Keberadaan ulin di alam sangat terbatas. Lamanya waktu tumbuh serta rendahnya kelulushidupan anakan menyebabkan jumlah ulin semakin menurun. Apalagi kegiatan eksploitasi berlebihan tanpa diimbangi pelestarian turut mendukung punahnya ulin di Kalimantan. Status konservasi jenis ulin 
menurut Red List Species IUCN (International Union for the Conservation of Nature Resources) dimasukkan dalam kategori rawan (vulnerable) yang berarti bahwa jenis ini di alam menghadapi resiko tinggi terhadap kepunahan dalam waktu dekat (IUCN, 2016).

Pohon ulin telah masuk pula dalam daftar Appendix II Convention on International Trade in Endangered Species of Wild Fauna and Flora (CITES) sebagai flora yang hampir punah dan tidak bisa diperdagangkan (CITES, 2016). Bahkan pemerintah telah menyatakan perlindungan dan pengawetan ulin melalui : UndangUndang No. 5 Tahun 1990 tentang Konservasi Sumber Daya Hayati dan Ekosistemnya, Peraturan Pemerintah No. 68 Tahun 1998 tentang KSA dan KPA, Peraturan Pemerintah No. 7 Tahun 1999 tentang Pengawetan Tumbuhan dan Satwa Liar, Kepmenhut No.447/Kpts-II/2003 tentang Tata Usaha Pengambilan atau Penangkapan dan peredaran TSL, Permenhut No. P.57/Menhut-II/2008 tentang Arahan Strategis Konservasi Spesies Nasional, serta Strategi dan Rencana Aksi Keanekaragaman Hayati Nasional yang biasa kita kenal dengan IBSAP (Indonesian Biodiversity Strategy and Action Plan) tahun 2015-2020 (BAPPENAS, 2016).

Taman Nasional Kutai (TNK) adalah kawasan konservasi yang disebut-sebut sebagai "benteng terakhir hutan tropis basah dataran rendah" di Kalimantan Timur. TNK memiliki berbagai tipe vegetasi utama yaitu hutan pantai/mangrove, hutan rawa air tawar, hutan kerangas, hutan genangan dataran rendah, hutan ulin/meranti/kapur dan hutan Dipterocarpaceae campuran. TNK merupakan perwakilan hutan ulin yang paling luas di Indonesia (TNK, 2014). Bahkan di salah satu bagian kawasan TNK yaitu Kawasan Konservasi Sangkima terdapat pohon ulin yang tercatat sebagai pohon tertinggi dan terbesar di Indonesia (TNK, 2014).

Problematika keberadaan ulin juga ditemui pada kawasan konservasi dimaksud, dimana kegiatan eksploitasi bersifat ekstraktif dan ilegal guna memenuhi kebutuhan masyarakat di sekitar maupun di luar kawasan yang menyebabkan kemerosotan secara kualitas maupun kuantitas sumberdaya hutan pada habitatnya (Rambey, 2010).
Dengan demikian budidaya ulin sebaiknya dilakukan untuk mengatasi kemorosotan jenis ini, dengan mempertimbangkan seluruh aspek persyaratan tumbuhnya di alam, termasuk interaksinya dengan jenis tumbuhan lainnya.

Dalam suatu komunitas tumbuhan hutan terjadi interaksi antara spesies anggota populasi (Indriyanto, 2006). Ada spesies yang harus menumpang hidup pada tumbuhan lain, ada pula yang membutuhkan naungan dari tumbuhan lain untuk hidup, sehingga mereka dapat tumbuh berdampingan membentuk sebuah komunitas hutan.

Menurut Kurniawan et al (2008) hubungan ketertarikan untuk tumbuh bersama ini dikenal dengan asosiasi yang dapat bersifat positif maupun negatif atau tidak berasosiasi. Informasi mengenai asosiasi ini sangat penting sebagai bahan pertimbangan dalam upaya untuk mengoptimalkan budidaya jenis ulin. Oleh karena itu, penelitian ini bertujuan untuk mengetahui asosiasi jenis ulin dengan pohonpohon dominan di kawasan Konservasi Sangkima, TNK sebagai penunjang upaya pembudidayaan jenis-jenis tersebut dalam rangka pengembangan tanaman ulin.

\section{METODOLOGI PENELITIAN}

\section{A. Waktu dan Lokasi}

Penelitian dilakukan pada bulan Juni 2012 di kawasan Konservasi Sangkima, Taman Nasional Kutai Kabupaten Kutai Timur, Provinsi Kalimantan Timur. Areal Seksi Konservasi Sangkima merupakan salah satu kawasan wisata alam yang menjadi kebanggaan TNK, memiliki total luasan $\pm 61.641 \mathrm{H} \backslash$ ha atau $31 \%$ dari luas keseluruhan kawasan TNK 198.629 ha.

Bentang alam kawasan seksi konservasi Sangkima terdiri dari sebelah selatan sungai Sangkima, sebelah barat hutan hujan tropis, sebelah utara perbukitan dan sebelah timur merupakan pantai pasir putih dan vegetasi bakau.

\section{B. Alat dan Bahan}

Alat yang digunakan adalah : kompas, GPS, roll meter, phi-band, ATK dan Kamera. Bahan yang digunakan sebagai objek penelitian adalah pohon ulin (E. zwageri). 
C. Prosedur Penelitian

1. Penentuan dan Pembuatan Plot Pengamatan

Penentuan plot menggunakan cara Purposive sampling di areal yang memiliki potensi akan keberadaan jenis ulin (E. zwageri) di lokasi tersebut. Plot penelitian berbentuk bujur sangkar dengan luas 1 ha (100 $\mathrm{m} \times 100 \mathrm{~m}$ ) yang dibagi menjadi 25 sub-petak ukur berukuran $20 \mathrm{~m}$ x $20 \mathrm{~m}$.

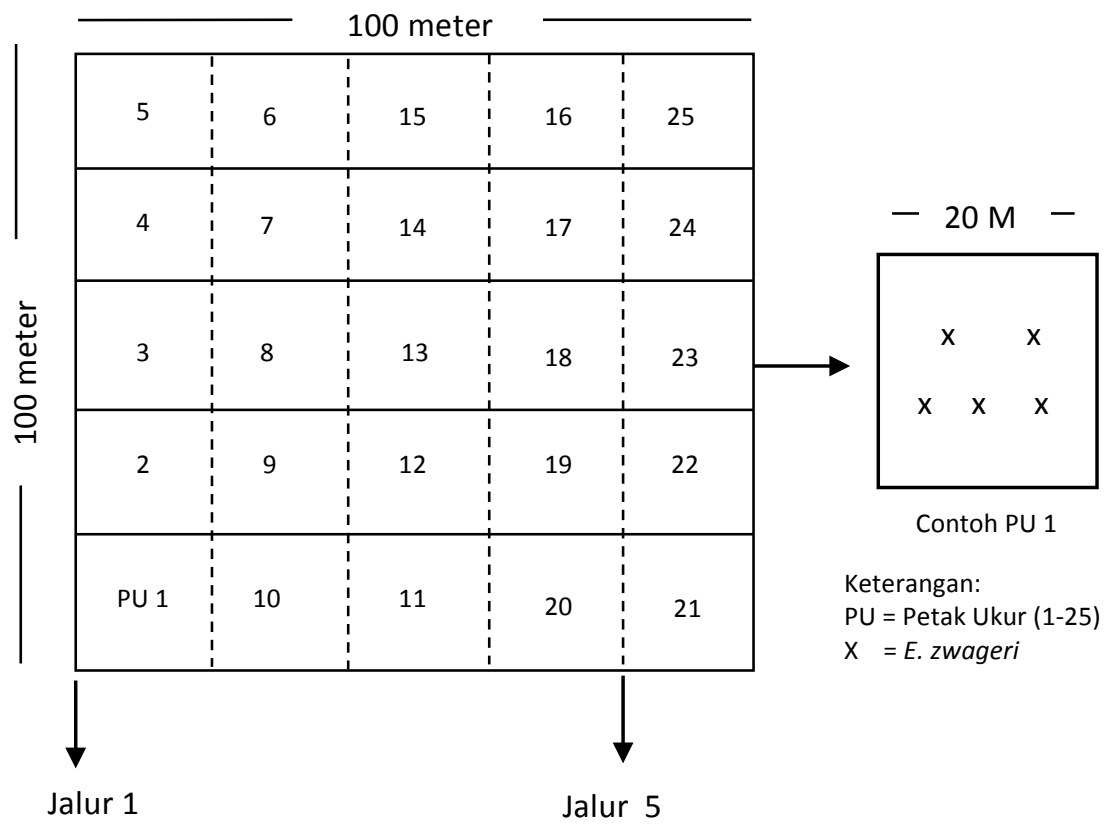

Gambar 1. Desain Plot untuk inventarisasi pohon

Figure 1. Plot design of tree inventory

2. Pengambilan data

Data yang dikumpulkan meliputi inventarisasi jenis-jenis pada tingkat pohon berdiameter di atas $10 \mathrm{~cm}$, pengambilan data posisi pohon (x\&y) seluruh jenis pada tingkat pohon dan pengambilan titik koordinat.

\section{Analisis Data}

Data yang dikumpulkan dianalisis dengan menghitung Frekuensi Relatif (FR), Kerapatan Relatif (KR), Dominansi Relatif dan Indeks Nilai Penting (INP) dari masingmasing jenis pohon yang diinventarisasi dengan menggunakan rumus dari MuellerDombois dan Ellenberg (1974) sebagai berikut:

$$
\begin{aligned}
& \mathrm{KR}(\%)=\frac{\text { Jumlah individu suatu jenis dalam plot }}{\text { Jumlah individu seluruh jenis dalam plot }} \times 100 \\
& \text { FR }(\%)=\frac{\text { Jumlah kehadiran suatu jenis dalam plot }}{\text { Jumlah kehadiran seluruh jenis dalam plot }} \text { X } 100 \\
& \mathrm{DR}(\%)=\frac{\text { Jumlah Luas Bidang Dasar suatu jenis }}{\text { Jumlah Luas Bidang Dasar seluruh jenis }} \times 100 \\
& \operatorname{INP}(\%) \quad=\quad \mathrm{KR}+\mathrm{FR}+\mathrm{DR}
\end{aligned}
$$

Kemudian analisa untuk mengetahui adanya asosiasi jenis-jenis pohon dibuat dengan menggunakan metode 2 x 2
Contingency Table (Greig-Smith, 1964; Kershaw, 1964). Dalam hal ini hanya jenisjenis pohon utama (INP $>10 \%$ ) saja yang 
diikutkan dalam analisis. Bentuk kontingensi tabel untuk asosiasi antara dua jenis adalah

Tabel 1. Bentuk tabel contingency

Table 1. Form of contingency table sebagai berikut :

\begin{tabular}{lllll}
\hline & & \multicolumn{3}{c}{ Spesies $\boldsymbol{A}$} \\
\cline { 3 - 5 } & & + & - & Jumlah \\
\hline \multirow{2}{*}{ Spesies B } & + & $\mathrm{a}$ & $\mathrm{b}$ & $\mathrm{a}+\mathrm{b}$ \\
& - & $\mathrm{c}$ & $\mathrm{d}$ & $\mathrm{c}+\mathrm{d}$ \\
& Jumlah & $\mathrm{a}+\mathrm{c}$ & $\mathrm{b}+\mathrm{d}$ & $\mathrm{N}=\mathrm{a}+\mathrm{b}+\mathrm{c}+\mathrm{d}$ \\
\hline
\end{tabular}

Sumber : diolah dari data primer

Keterangan :
a : Jumlah petak yang mengandung jenis A dan jenis B.
b : Jumlah petak yang mengandung jenis A saja, jenis B tidak
c : Jumlah petak yang mengandung jenis B saja, jenis A tidak
d : Jumlah petak yang tidak mengandung jenis A dan jenis B (diluar jenis A dan jenis B)
$\mathrm{N}$ : Jumlah semua petak

Sedangkan untuk mengukur besarnya penyimpangan antara nilai pengamatan dengan

nilai harapan digunakan "Chi-square test", seperti dibawah ini:

$$
X^{2}=\frac{(a d-b c)^{2} \times N}{(a+b)(c+d)(a+c)(b+d)}
$$

Nilai ini dibandingkan dengan nilai chisquare $\left(\mathrm{X}^{2}\right)$ tabel pada derajat bebas $(d f)$ sama dengan satu pada taraf uji $1 \%(6,63)$ dan $5 \%$ $(3,84)$. Berdasarkan kedua nilai chi-square tersebut, dapat diambil suatu kesimpulan, sebagai berikut :

1. Apabila nilai chi-square hitung lebih besar dari nilai chi-square tabel, maka asosiasi bersifat nyata pada taraf uji tersebut.

2. Apabila nilai chi-square hitung kecil dari nilai chi-square, maka asosiasi bersifat tidak nyata pada taraf uji tersebut.

3. Kemudian dilakukan perhitungan koefisien asosiasi untuk mengetahui besarnya nilai hubungan antar dua jenis dalam satu komunitas hutan (asosiasi positif atau negatif) dilakukan perhitungan koefisien asosiasi atau nilai kekerabatan dengan menggunakan rumus yang dikemukakan oleh Ludwig dan Reynold, (1988).

\section{HASIL DAN PEMBAHASAN}

\section{A. Komposisi Jenis Tumbuhan}

Berdasarkan hasil inventarisasi jenis pohon pada plot pengamatan, memperlihatkan bahwa secara keseluruhan ditemukan 53 jenis dengan jumlah pohon sebanyak 263 pohon. Analisa vegetasi dilakukan untuk pohon yang berdiameter $\geq 10 \mathrm{~cm}$. Jenis pohon yang mempunyai Indeks Nilai Penting (INP) di plot pengamatan ulin, disajikan pada Tabel 2 .

Tabel 2. Indeks Nilai Penting (INP) jenis pohon pada plot pengamatan

Table 2. Importance Value Index (IVI) of some species in observation plot

\begin{tabular}{clcccc}
\hline No. & \multicolumn{1}{c}{ Nama Latin } & FR & KR & DR & INP (\%) \\
\hline 1 & Eusideroxylon zwageri & 10,59 & 18,25 & 30,99 & 59,83 \\
\hline 2 & Shorea leprosula & 6,47 & 8,37 & 7,19 & 22,03 \\
\hline 3 & Cananga odorata & 7,60 & 7,65 & 5,55 & 20,80 \\
\hline 4 & Dracontomelon dao & 7,22 & 4,71 & 3,02 & 14,95 \\
\hline 5 & Dipterocarpus confertus & 2,28 & 2,94 & 7,63 & 12,85 \\
\hline 6 & Macaranga gigantea & 3,42 & 4,12 & 2,94 & 10,48 \\
\hline
\end{tabular}

Sumber : pengolahan data primer 2012. 
Dalam pengamatan ini ditemukan enam jenis pohon yang mempunyai INP 10,48\%$59,83 \%$. INP tertinggi menunjukkan jenis pohon yang banyak ditemukan di lokasi penelitian (Gambar 2). Ulin merupakan jenis pohon yang mempunyai INP tertinggi dan mendominasi tegakan di lokasi penelitian. Kemudian Shorea leprosula menempati urutan tertinggi kedua dengan INP 22,03\%, sedangkan jenis pohon yang mempunyai INP terendah adalah Macaranga gigantea, yaitu 10,48\%. Dari hasil INP terlihat bahwa ulin memiliki INP paling besar dibandingkan jenis lainnya, hal itu berarti jenis tersebut mempunyai peranan yang paling besar dibandingkan dengan jenis lainnya (Gambar 3). Menurut Sidiyasa (2011) sebagai tegakan ulin selalu menempati urutan pertama, diikuti oleh spesies pohon lain yang memiliki tingkat kepentingan tinggi yang ada di bawahnya.

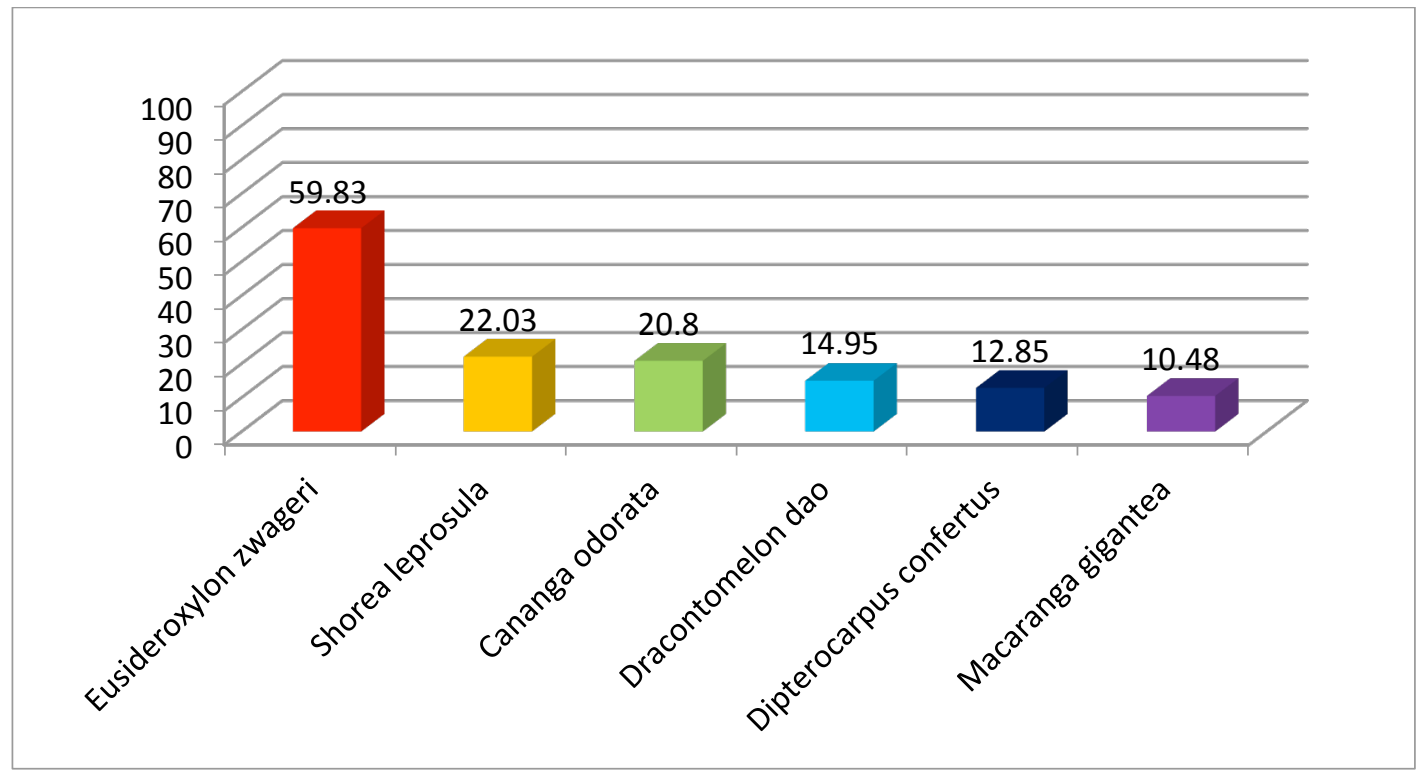

Gambar 2. Indeks Nilai Penting (INP) jenis pohon pada plot pengamatan Figure 2. Importance Value Index (IVI) of some species in observation plot

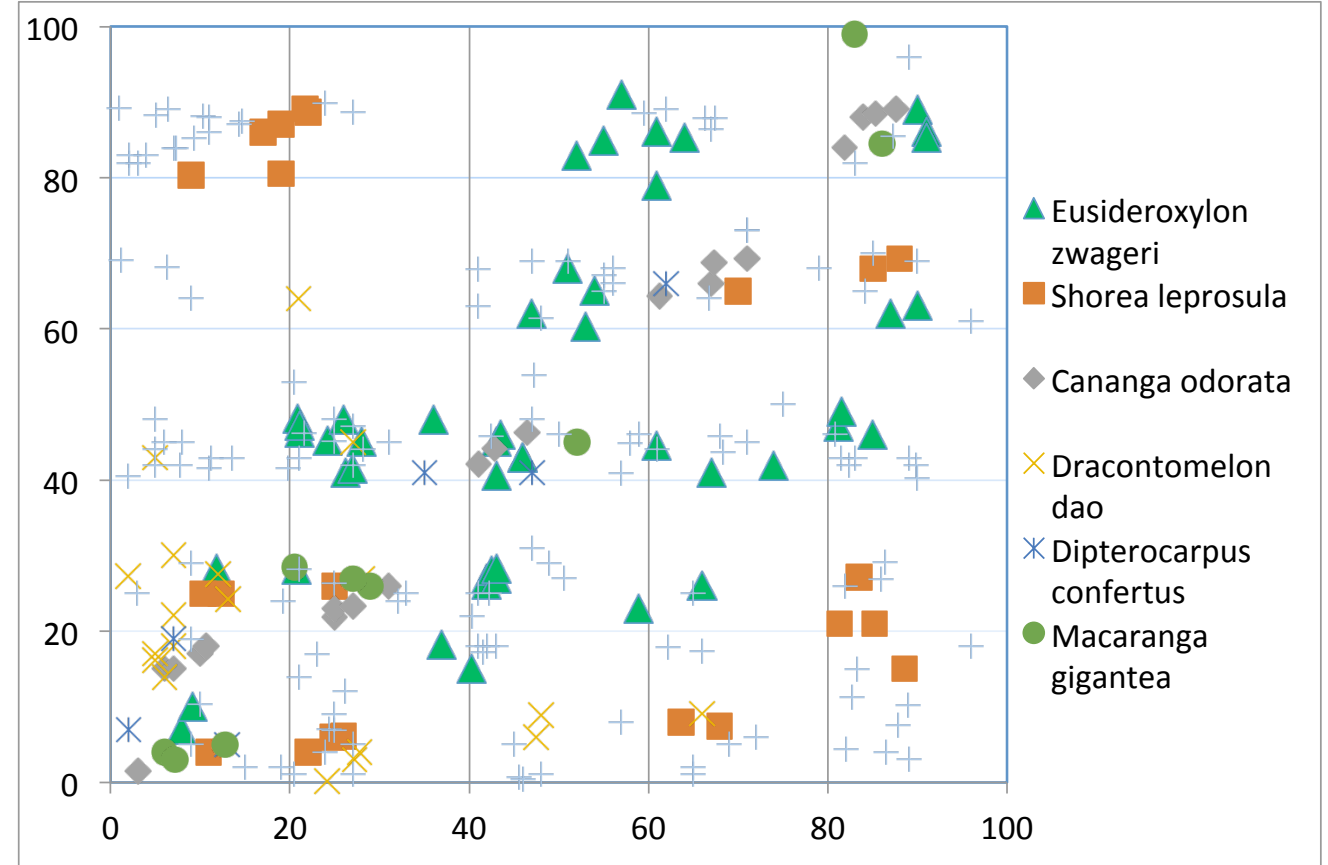

Gambar 3. Peta sebaran jenis pohon pada Plot Pengamatan

Figure 3. Map of tree species distribution in observation plot 


\section{B. Sebaran pohon Ulin (E. zwageri) berdasarkan kelerengan}

Penyebaran pohon ulin berdasarkan kelerengan disajikan pada Tabel 3. Jumlah pohon ulin ditemukan pada empat kelas kelerengan $8-15 \%$ s/d $>40 \%$, dengan sebaran yang tidak merata pada keempat kelas kelerengan tersebut. Menurut Pradjadinata dan Murniati (2014), Ulin biasanya tumbuh secara menyebar atau mengelompok dengan kanopi dominan dan juga ditemui sebagai tegakan tersendiri dan ulin biasanya ditemukan berasosiasi dengan jenis-jenis Koompasia spp, Shorea spp dan Intsia spp.

Tabel 3. Sebaran ulin (E. zwageri) berdasarkan kelas kelerengan

Table 3. Ironwood (E. zwageri) Distribution based on Slope Class

\begin{tabular}{ccc}
\hline Jenis & Kelas Kelerengan (\%) & Jumlah Pohon \\
\hline \multirow{3}{*}{ Eusideroxylon zwageri } & $8-15$ & 9 \\
\cline { 2 - 3 } & $15-25$ & 11 \\
\cline { 2 - 3 } & $25-40$ & 17 \\
\cline { 2 - 3 } & $>40$ & 11 \\
\hline
\end{tabular}

Sumber : Pengolahan data primer 2012.

Dari Tabel 3 terlihat bahwa jumlah pohon terbanyak ditemukan pada kelerengan $25-40 \%$ dengan 17 pohon, kemudian menyebar merata pada kelerengan $15-25 \%$ dan $>40 \%$ dengan 11 pohon. Hal ini diduga karena Ulin (E. zwageri) beradaptasi dengan baik pada lahan miring atau tidak tergenang air (Heyne, 1987).

\section{Asosiasi Ulin (E. zwageri) dengan Jenis Lain}

Hasil perhitungan INP diperoleh enam jenis pohon dominan yang memiliki INP > $10 \%$ seperti pada Tabel 2. Berdasarkan Tabel
4 terlihat bahwa hasil uji korelasi 2 jenis antara Ulin dengan 6 jenis pohon yang dominan, dimana nilai $X^{2}$ hitung semuanya lebih besar dari $X^{2}$ tabel $(0,01)=6,63$. Hal ini mengindikasikan bahwa ada korelasi yang sangat nyata antara dua belas jenis tersebut dengan Ulin. Dilihat dari perhitungan koefisien asosiasi $(\mathrm{C})$ yang digunakan sebagai parameter hubungan kekerabatan antara Ulin dengan dua belas jenis tersebut. Data nilai asosiasi dan koefisien asosiasi jenis Ulin dengan jenis lainnya disajikan pada Tabel 4.

Tabel 4. Hasil perhitungan nilai asosiasi dan koefisien asosiasi jenis Ulin (E. zwageri) dengan jenis lain.

Table 4. The Calculation of Association Value and Association Coefisien of Ironwood (E. zwageri) with Others Species.

\begin{tabular}{|c|c|c|c|c|c|c|c|}
\hline \multirow{2}{*}{ No } & \multirow{2}{*}{ Jenis } & \multicolumn{2}{|c|}{$\mathrm{X}^{2}$ tabel } & \multirow{2}{*}{$\mathrm{X}^{2}$ hitung } & \multicolumn{3}{|c|}{ Eusideroxylon zwageri } \\
\hline & & $5 \%$ & $1 \%$ & & & & $\mathbf{C}(+/-)$ \\
\hline 1 & Elmeria chiampaca & 3,84 & 6,63 & 10,15 & $*$ & - & 0,09 \\
\hline 2 & Octomeles sumatrana & 3,84 & 6,63 & 10,15 & $*$ & - & 0,09 \\
\hline 3 & Ficus albifila & 3,84 & 6,63 & 9,77 & $*$ & + & 0,75 \\
\hline 4 & Garcinia mangostana & 3,84 & 6,63 & 7,69 & $*$ & - & 0,04 \\
\hline 5 & Glochidion $s p$ & 3,84 & 6,63 & 7,69 & $*$ & - & 0,04 \\
\hline 6 & Knema cinerea & 3,84 & 6,63 & 7,69 & $*$ & - & 0,04 \\
\hline 7 & Litsea spp & 3,84 & 6,63 & 7,69 & $*$ & - & 0,04 \\
\hline 8 & Nephelium sp & 3,84 & 6,63 & 7,69 & $*$ & - & 0,04 \\
\hline 9 & Nuclea spp & 3,84 & 6,63 & 7,69 & $*$ & - & 0,04 \\
\hline 10 & Vitex fubescens & 3,84 & 6,63 & 7,69 & $*$ & - & 0,04 \\
\hline 11 & Neo nuclea exelsa & 3,84 & 6,63 & 7,47 & $*$ & - & 0,09 \\
\hline 12 & Pometia pinnata & 3,84 & 6,63 & 5,18 & $* *$ & - & 0,07 \\
\hline
\end{tabular}

Sumber : Pengolahan data primer 2012.

Keterangan: ${ }^{+}$: Asosiasi positif,

: Asosiasi negatif,

$*$ : Berbeda sangat nyata pada taraf uji $1 \%$,

${ }^{* *}$ : Berbeda nyata pada taraf uji 5\%, 
Dari hasil perhitungan (Tabel 4) terlihat nilai koefisien asosiasi lebih banyak bernilai negatif, walaupun ada hubungan yang sangat nyata, hal ini menggambarkan bahwa jenis Ulin dengan jenis lainnya saling merugikan satu dengan lainnya atau mempunyai respon adaptasi berbeda dengan lingkungan yang dapat diartikan bahwa terjadi kompetisi dalam hal cahaya, nutrisi, ruang tumbuh dan kebutuhan lainnya antar kedua jenis tersebut. Menurut Whittaker (1975) dalam Sofian (2008), bahwa asosiasi negatif menunjukkan jenis yang bersangkutan cenderung sedikit ditemukan bersama atau tidak mau hidup bersama. Dugaan lain bahwa asosiasi negatif menimbulkan modifikasi lingkungan dan jenis-jenis tertentu yang memproduksi racun. Karena pengaruh yang saling merugikan tersebut menyebabkan jenis yang dirugikan tidak dapat bertahan hidup.

Dan dari hasil perhitungan asosiasi terlihat bahwa ada satu nilai koefisien positif sangat nyata, yaitu antara Ulin dengan Ficus albifila, hal ini menunjukkan bahwa jenis tersebut mampu hidup secara bersama-sama dan memiliki ketergantungan antara satu dengan yang lainnya. Kebersamaan kedua jenis tersebut dikarenakan memiliki respon yang sama atau hampir sama terhadap perubahan faktor lingkungan yang bersifat ekstrim. Stein et al (2014) mengemukakan bahwa bila jenis berasosiasi secara positif maka akan menghasilkan hubungan spasial positif terhadap pasangannya. Jika satu pasangan didapatkan dalam sampling, maka kemungkinan besar akan ditemukan pasangan lainnya tumbuh di dekatnya.

\section{KESIMPULAN DAN SARAN}

\section{A. Kesimpulan}

Hasil analisa menunjukkan bahwa pada kawasan Konservasi Sangkima Taman Nasional Kutai, Kabupaten Kutai Timur Provinsi Kalimantan Timur ditemukan 53 jenis dengan jumlah pohon sebanyak 263 pohon, dimana Ulin merupakan jenis pohon yang mempunyai INP tertinggi dan mendominasi tegakan di lokasi penelitian, dengan nilai $59,83 \%$. Jenis Ulin ditemukan pada empat kelas kelerengan $8-15 \%$ s/d $>40 \%$, dengan sebaran yang tidak merata pada keempat kelas kelerengan tersebut. Dan terdapat satu jenis yang berasosiasi positif sangat nyata dengan Ulin diantara duabelas jenis pohon dominan di kawasan Konservasi Sangkima, yaitu jenis $S$. leprosula dan F. albifila.

\section{B. Saran}

Berdasarkan informasi asosiasi jenis Ulin dengan jenis lain dalam penelitian ini, perlu diperhatikan bahwa jenis-jenis yang berasosiasi positif ( $S$. leprosula dan $F$. albifila) agar dapat pula dikembangkan seiring dengan pengembangan jenis Ulin (E. zwageri), sehingga pengembangan jenis istimewa ini dapat berjalan sesuai dengan yang diharapkan.

\section{DAFTAR PUSTAKA}

BAPPENAS. (2016). Indonesian Biodiversity Strategy and Action Plan. Diunduh tanggal 18 Pebruari 2016.

CITES. (2016). Convention on International Trade in Endangered Species of Wild Fauna and Flora. Diunduh tanggal 29 Juni 2016.

Greig-Smith, P. (1964). Quantitative and Dynamic Plant Ecology. Second Edition, Butterworts. London.

Heyne, K. (1987). Tumbuhan Berguna Indonesia. Terjemahan. Yayasan Sarana Wana Jaya. Jakarta.

Indriyanto. (2006). Ekologi Hutan. PT. Bumi Aksara. Jakarta.

IUCN. (2016). International Union for the Conservation of Nature Resources. Diunduh tanggal 10 Maret 2016.

Kershaw, K. A. (1964). Quantitative and Dynamic Plant Ecology. American Elsevier P. Company. New York.

Kurniawan, A., N.K.E., Undaharta dan I.M.R. Pendit. (2008). Asosiasi Jenis-jenis Pohon Dominan di Hutan Dataran Rendah Cagar Alam Tangkoko, Bitung, Sulawesi Utara, Jurnal Biodiversity 9 (3) :199-203. Surakarta.

Ludwig, J. A dan J. F. Reynolds, (1988). Statistical Ecology. $2^{\text {nd }}$ ed. London: Edward Arnold (Publisher) Co. Ltd.

Mueller-Dumbois, D., and H. Ellenberg. (1974). Aims and Methode of Vegetation Ecology. John Willey and Sons. New York, London, Sydney, Toronto.

Pradjadinata, S. dan Murniati. (2014). Pengelolaan dan Konservasi Jenis Ulin (E. zwagery Tejsm., \& Binn). Jurnal Penelitian Hutan dan Konservasi Alam. 11 (3), Desember 2014 :205-223.

Rambey, R. (2010). Status Keragaman Genetik Ulin (Eusideroxylon zwageri) dan Implikasi 
Konservasinya. Program Pascasarjana. IPB. Bogor. Tidak Dipublikasikan.

Sidiyasa, K. (2011). Sebaran, Potensi Dan Pengelolaan Ulin Di Indonesia. Prosiding Lokakarya Nasional "Status Konservasi Dan Formulasi Strategi Konservasi Jenis-Jenis Pohon Yang Terancam Punah (Ulin, Eboni Dan Michelia)". Pusat Penelitian Dan Pengembangan Konservasi Dan Rehabilitasi Badan Litbang Kehutanan Bekerjasama Dengan ITTO. Bogor.

Sofian, M. (2008). Assosiasi dan Sebaran Jenis Pohon Penghasil Buah Tengkawang (Shorea pinanga R.Scheffer) pada KHDTK Labanan, Kabupaten Berau Hutan Alam Labanan, Kabupaten Berau. Skripsi Program Studi Pertanian. Jurusan Manajemen Hutan. Universitas Tujuh Belas Agustus 1945. Samarinda.
Stein, A., K., Gerstner, and H., Kreft. (2014). Environmental Heterogeneity as a Universal Driver of Species Richness Across Taxa, Biomes, and Spatial Scale. Review and Synthesis. Ecology Letters : $1-16$.

TNK, (2014). Taman Nasional Kutai. Website http://TN\%20INDO-ENGLISH/tn_kutai.html. Diakses tanggal 27 januari 2014.

Wahjono, J., and R. Imanuddin, (2011). Sebaran, Potensi Dan Pertumbuhan/Riap Ulin (E. Zwageri Teijsm \& Binn) di Hutan Alam Bekas Tebangan di Kalimantan. Prosiding Lokakarya Nasional "Status Konservasi Dan Formulasi Strategi Konservasi Jenis-Jenis Pohon Yang Terancam Punah (Ulin, Eboni Dan Michelia)". Pusat Penelitian Dan Pengembangan Konservasi Dan Rehabilitasi Badan Litbang Kehutanan Bekerjasama Dengan ITTO. Bogor. 